\title{
Sedação, analgesia e bloqueio neuromuscular na unidade de terapia intensiva
}

\author{
Sedation, analgesia and neuromuscular blockade \\ in the intensive care unit
}

\author{
Marcos L. Miranda* \\ Carlos D. A. Bersot \\ Nivaldo R. Villela
}

\begin{abstract}
Resumo
Pacientes críticos invariavelmente estão ansiosos, agitados, confusos, desconfortáveis e/ou com dor. Neste contexto, analgésicos e sedativos são amplamente utilizados nas unidades de terapia intensiva (UTIs). Algumas vezes, em casos mais específicos, o bloqueio neuromuscular também é utilizado. A administração de agentes sedativos, analgésicos e bloqueadores neuromusculares na UTI tem aspectos próprios e, em muitos casos, seu uso se diferencia daquele encontrado no ambiente cirúrgico. Na UTI, em decorrência do pior estado clínico dos pacientes e do prolongado tempo de tratamento necessário, alcançar adequada (mas não excessiva) sedação é um processo complexo. Analgésicos e sedativos empregados no âmbito das UTIs são extremamente potentes e as necessidades e o metabolismo destas drogas em pacientes críticos são, muitas vezes, imprevisíveis. Embora os médicos intensivistas saibam que o tratamento com sedativos e analgésicos pode influenciar na evolução do quadro clínico de seus pacientes,
\end{abstract}

ainda existem falhas no que concerne ao reconhecimento e controle da dor e do estresse. Os médicos devem ter consciência dos efeitos de cada droga e devem empregar estratégias que maximizem benefícios enquanto minimizam os riscos. Tanto o excesso de sedação quanto a sedação insuficiente são danosos. Neste campo, importantes avanços têm sido alcançados através da titulação de medicações guiada por metas, evitando assim o excesso ou a insuficiência de efeitos. Visando a melhoria dos cuidados prestados aos pacientes críticos, são apresentados conceitos fundamentais sobre analgesia, sedação e bloqueio neuromuscular na unidade de terapia intensiva. O conceito de sedação paliativa, com o intuito de reduzir a consciência, oferecer conforto e aliviar a angústia do paciente ou outros sintomas intoleráveis e/ou refratários, também é apresentado e discutido.

Descritores: Sedação consciente; Sedação profunda; Analgesia; Medição da dor; Bloqueio neuromuscular; Terapia intensiva; Cuidados paliativos na terminalidade da vida. 


\section{Abstract}

Critically ill patients are invariably anxious, agitated, confused, uncomfortable and/or with pain. In this context, analgesics and sedatives are widely used in intensive care units (ICUs). Sometimes, in more specific cases, neuromuscular blockade is also used. The administration of sedatives, analgesics and neuromuscular blocking agents in the ICU has its own aspects and in many cases their use differs from that found in the surgical environment. In the ICU, due to the worse clinical status of patients and prolonged treatment time required, achieving adequate but not excessive sedation is a complex process. Sedatives and analgesics used in the ICUs are extremely potent and the needs and metabolism of these drugs in critically ill patients are often unpredictable. Although ICU physicians know that treatment with sedatives and analgesics can influence the evolution of the clinical status of their patients, there are still gaps regarding the recognition and management of pain and stress. Physicians should be aware of the effects of each drug and should employ strategies that maximize benefits while minimizing the risks. Both excessive as insufficient sedation are harmful. In this field, important advances have been achieved by goal-directed titration of medications, thereby avoiding excessive or insufficient effects. Aiming to improve the care provided to critically ill patients, fundamental concepts of analgesia, sedation and neuromuscular blockade in the intensive care unit are presented. The concept of palliative sedation with the purpose of reducing awareness, provide comfort and relieve the patient's distress or other intolerable and/or refractory symptoms is also presented and discussed.

Keywords: Conscious sedation; Deep sedation; Analgesia; Pain measurement; Neuromuscular blockade; Intensive care; Hospice care.

\section{Introdução}

Pacientes críticos invariavelmente estão ansiosos, agitados, confusos, desconfortáveis e/ou com dor, o que geralmente decorre do ambiente adverso encontrado nas unidades de terapia intensiva (UTIs). Neste contexto, abordagens terapêuticas, farmacológicas e ambientais, a fim de atenuar as respostas ao ambiente/estímulos, merecem atenção especial.

Analgésicos e sedativos são amplamente utilizados na UTI para atingir o conforto do paciente e a tolerância ao ambiente, além de controlarem a privação de sono, a dor, a ansiedade, o delirium e outros estímulos nocivos. ${ }^{1} \mathrm{O}$ adequado controle da dor contribui para a melhora da função pulmonar e para um desmame ventilatório mais rápido, além de auxiliar na redução do consumo miocárdico de oxigênio. Algumas vezes, o bloqueio neuromuscular também é utilizado, mas como último recurso ou em casos específicos.

O conhecimento e a prática do uso de sedativos, analgésicos e bloqueadores neuromusculares são provenientes do ambiente cirúrgico. No entanto, a utilização sustentada desses agentes na UTI tem aspectos diferentes daqueles encontrados no período perioperatório: na UTI, há necessidade de sedação a longo prazo de pacientes que frequentemente têm insuficiência de múltiplos órgãos e instabilidade hemodinâmica; além disso, a total imobilização é raramente necessária. Preferencialmente, os pacientes da UTI devem receber o mínimo de sedação necessária às suas necessidades atuais, ou seja, sedação e analgesia suficientes para tolerarem os estímulos nocivos e ficarem livres de dor enquanto continuam despertáveis quando estimulados.

\section{Sedação}

A sedação envolve um amplo espectro de condições desde um simples estado de cooperação, tranquilidade e vigília, com orientação temporoespacial preservada, até estados de depressão das respostas aos comandos, podendo ou não incluir a hipnose. Em níveis mais profundos de sedação, podem ocorrer depressão respiratória e instabilidade hemodinâmica. As principais drogas sedativas utilizadas na UTI são apresentadas no quadro $1 .{ }^{2}$ 
Quadro 1. Principais drogas sedativas utilizadas na UTI

\begin{tabular}{|c|c|c|c|c|c|c|c|}
\hline $\begin{array}{l}\text { Mecanismo de } \\
\text { ação }\end{array}$ & $\begin{array}{l}\text { Agonista } \\
\text { receptor GABA }\end{array}$ & $\begin{array}{l}\text { Agonista } \\
\text { receptor } \\
\text { GABA }\end{array}$ & $\begin{array}{l}\text { Agonista } \\
\text { receptor GABA }\end{array}$ & $\begin{array}{l}\text { Agonista } \\
\text { receptor GABA }\end{array}$ & $\begin{array}{l}\text { Agonista receptor } \\
\text { NMDA }\end{array}$ & $\begin{array}{l}\text { Agonista receptor alfa- } \\
2 \text { adrenérgico }\end{array}$ & $\begin{array}{c}\text { Antagonista } \\
\text { dopaminérgico }\end{array}$ \\
\hline $\begin{array}{l}\text { Início de ação } \\
\text { (min.) }\end{array}$ & $0,5-5$ & $0,5-1$ & $0,5-1$ & $0,5-1$ & $0,5-1$ & $5-10$ & $3-20$ \\
\hline $\begin{array}{l}\text { Duração do } \\
\text { efeito }\end{array}$ & 2 horas & 4-15 min. & $3-10 \mathrm{~min}$. & 3-5 min. & 5-15 min. & $20 \mathrm{~min}$. & 4-8 horas \\
\hline $\begin{array}{l}\text { Dose inicial } \\
\text { (intravenosa) }\end{array}$ & $\begin{array}{l}0,02-0,8 \mathrm{mg} / \mathrm{kg} \\
\text { até } 30 / 30 \mathrm{~min} . ; \\
\text { infusão 0,02-0,1 } \\
\mathrm{mg} / \mathrm{kg} / \mathrm{h}\end{array}$ & $\begin{array}{l}\text { 3-5 mg/Kg; } \\
\text { Infusão 0,01- } \\
0,1 \mathrm{mg} / \mathrm{Kg} / \mathrm{h}\end{array}$ & $\begin{array}{l}\text { 0,05-1mg/Kg; } \\
\text { Infusão 5-75 } \\
\mathrm{mcg} / \mathrm{Kg} / \mathrm{min}\end{array}$ & $0,3 \mathrm{mg} / \mathrm{Kg}$ & $0,5-4,5 \mathrm{mg} / \mathrm{Kg}$ & $\begin{array}{l}1 \mathrm{mcg} / \mathrm{kg} \text { em } 10 \mathrm{~min} \text {; } \\
\text { Infusão 0,2-0,7 mcg/ } \\
\mathrm{Kg} / \mathrm{h}\end{array}$ & $0,5-10 \mathrm{mg}$ \\
\hline Vantagens & $\begin{array}{l}\text { Reversibilidade } \\
\text { (flumazenil). }\end{array}$ & $\begin{array}{l}\text { Curta } \\
\text { duração. }\end{array}$ & $\begin{array}{l}\text { Curta duração; } \\
\text { observação } \\
\text { neurológica } \\
\text { em pacientes } \\
\text { neurocríticos; } \\
\text { efeito } \\
\text { antiemético. }\end{array}$ & $\begin{array}{l}\text { Estabilidade } \\
\text { cardiovascular; } \\
\text { curta duração } \\
\text { de ação; mínima } \\
\text { depressão } \\
\text { ventilatória. }\end{array}$ & $\begin{array}{l}\text { Curta duração; } \\
\text { mínima depressão } \\
\text { ventilatória; } \\
\text { broncodilatação; } \\
\text { efeitos } \\
\text { analgésicos. }\end{array}$ & $\begin{array}{l}\text { Preserva a estrutura } \\
\text { do sono; não deprime } \\
\text { a ventilação; efeitos } \\
\text { analgésicos. }\end{array}$ & $\begin{array}{l}\text { Tratamento do } \\
\text { delirium }\end{array}$ \\
\hline Desvantagens & $\begin{array}{l}\text { Acúmulo; } \\
\text { depressão } \\
\text { ventilatória e } \\
\text { hemodinâmica; } \\
\text { agitação } \\
\text { paradoxal/ } \\
\text { delirium. }\end{array}$ & $\begin{array}{l}\text { Acúmulo } \\
\text { em doses } \\
\text { repetidas; } \\
\text { reações } \\
\text { alérgicas; } \\
\text { depressão } \\
\text { ventilatória e } \\
\text { cardíaca. }\end{array}$ & $\begin{array}{l}\text { Hipotensão; } \\
\text { depressão } \\
\text { ventilatória; } \\
\text { acidose; } \\
\text { irritação venosa } \\
\text { (dor); sepse. }\end{array}$ & $\begin{array}{l}\text { Náuseas e } \\
\text { vômitos; } \\
\text { irritação venosa } \\
\text { (dor); mioclônus; } \\
\text { supressão do } \\
\text { eixo hipotálamo- } \\
\text { hipófise-adrenal. }\end{array}$ & $\begin{array}{l}\text { Alucinação; } \\
\text { hipersalivação; } \\
\text { taquicardia e } \\
\text { hipertensão; } \\
\text { laringoespasmo. }\end{array}$ & $\begin{array}{l}\text { Hipertensão/ } \\
\text { hipotensão; } \\
\text { bradicardia. }\end{array}$ & $\begin{array}{l}\text { Alterações } \\
\text { extrapiramidais; } \\
\text { prolongamento } \\
\text { intervalo QT; } \\
\text { síndrome } \\
\text { neuroléptica } \\
\text { maligna; agitação } \\
\text { paradoxal; } \\
\text { hipotensão }\end{array}$ \\
\hline
\end{tabular}

\section{Analgesia}

A dor - uma experiência desagradável, subjetiva e complexa, de natureza sensorial ou emocional associada ou não à lesão tecidual real - é uma das piores experiências possíveis para os pacientes críticos e, infelizmente, uma das mais comuns. Aproximadamente 50\% dos pacientes clínicos internados na UTI referem dor $^{3}$ e em quase todos os pacientes que recebem cuidados intensivos algum tipo de analgesia deverá ser empregada. Diversos estudos apontam que a dor, em todos os níveis de atenção à saúde, é subdiagnosticada ou mal avaliada, subtratada e, algumas vezes, negligenciada. ${ }^{4}$ As drogas analgésicas podem ser divididas em opioides e não opioides (por exemplo, anti-inflamatórios não hormonais, cetamina, anestésicos locais, corticoides, anticonvulsivantes e $\alpha-2$ agonistas)., ${ }^{2,5}$ O uso de algoritmos no tratamento da dor é importante e ajuda na escolha da(s) melhor(es) droga(s) para as necessidades do paciente. Os principais opioides utilizados na UTI são apresentados no quadro $2 .^{6}$

\section{Bloqueio neuromuscular}

O uso de relaxantes neuromusculares na UTI é problemático e está relacionado a complicações, como a miopatia. As atuais recomendações são de que os relaxantes neuromusculares sejam utilizados para facilitar a intubação, auxiliar a adaptação à ventilação mecânica (principalmente quando são empregadas modalidades desconfortáveis, como a ventilação prona, a hipercapnia permissiva e o uso de altos níveis de pressão expiratória final positiva (PEEP) ou auxiliar no manejo da hipertensão intracraniana ou de espasmos musculares tetânicos, somente em pacientes nos quais o uso de sedativos e analgésicos em doses otimizadas foi insuficiente. ${ }^{7-9}$ Desta forma, o uso de bloqueadores neuromusculares permanece como último recurso e deve sempre ser precedido pela sedação efetiva e interrompido logo que possível, a fim de evitar complicações.

Os principais bloqueadores neuromusculares utilizados na UTI são apresentados no quadro 3. 
Quadro 2. Principais opioides utilizados na UTI

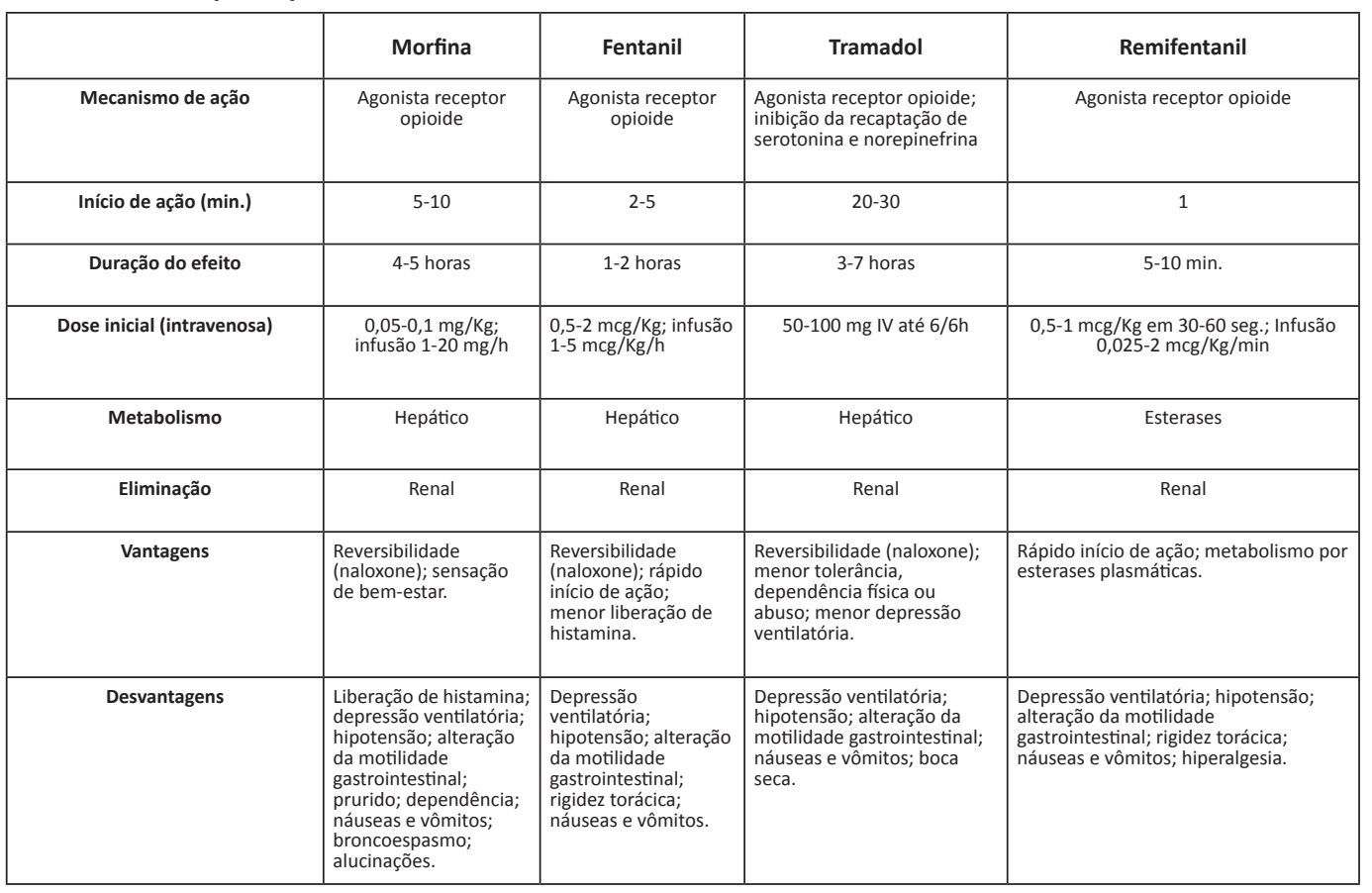

Quadro 3. Principais bloqueadores neuromusculares utilizados na UTI

\begin{tabular}{|c|c|c|c|}
\hline & Succinilcolina & Atracúrio & Pancurônio \\
\hline Mecanismo de ação & $\begin{array}{c}\text { Bloqueador neuromuscular } \\
\text { despolarizante }\end{array}$ & $\begin{array}{c}\text { Bloqueador neuromuscular não } \\
\text { despolarizante }\end{array}$ & $\begin{array}{c}\text { Bloqueador neuromuscular não } \\
\text { despolarizante }\end{array}$ \\
\hline Início de ação (min.) & $0,5-1$ & $1,5-3$ & $1,5-4$ \\
\hline Duração do efeito & Curta (5-10 min.) & Intermediária (20-35 min.) & Longa (60-90 min.) \\
\hline Dose inicial (intravenosa) & $1,0-1,5 \mathrm{mg} / \mathrm{Kg}$ & $0,5 \mathrm{mg} / \mathrm{Kg}$; Infusão 5-10 mcg/Kg/min & $0,1 \mathrm{mg} / \mathrm{Kg}$ \\
\hline Metabolismo & Esterases. & $\begin{array}{l}\text { Via de Hofmann; esterases. } \\
\text { Hepático mínimo (10\%); eliminação } \\
\text { renal (80\% da droga não modificada). }\end{array}$ & $\begin{array}{l}\text { Bloqueio neuromuscular prolongado } \\
\text { (quando necessário). }\end{array}$ \\
\hline Vantagens & $\begin{array}{l}\text { Facilitação da intubação; curta } \\
\text { duração. }\end{array}$ & $\begin{array}{l}\text { Metabolismo independente de } \\
\text { órgãos. }\end{array}$ & $\begin{array}{l}\text { Taquicardia; bloqueio neuromuscular } \\
\text { prolongado. }\end{array}$ \\
\hline Desvantagens & $\begin{array}{l}\text { Arritmias; hipertemia maligna; } \\
\text { intraocular. }\end{array}$ & Liberação de histamina; laudanosina. \\
\hline
\end{tabular}

\section{Uso de agentes anestésicos voláteis para sedação na unidade de terapia intensiva}

Há bastante tempo os agentes anestésicos voláteis são rotineiramente utilizados em procedimentos anestésicos no ambiente cirúrgico. Apesar desta larga experiência de uso, estas drogas têm papel apenas marginal para sedação nas UTIs. Os primeiros agentes voláteis eram hepatotóxicos e induziam arritmias, o que tornava inapropriado o seu uso por tempo prolongado em pacientes críticos. Entretanto, a síntese de agentes mais seguros que - como droga única, provêm sedação titulável, potente analgesia e relaxamento muscular, além de neuro e cardioproteção - tem gerado um interesse crescente no emprego destes fármacos para sedação em terapia intensiva. $\mathrm{O}$ acoplamento de dispositivos de conservação de anestésicos inalatórios ao circuito do ventilador mecânico, como o AnaConDa (Sedana Medical, Suécia), evita o desperdício do agente e reduz a contaminação do ambiente, solucionando um dos maiores empecilhos ao seu uso em ventiladores com circuito aberto de ventilação, encontrados nas UTIs. Mesnil e colaboradores mostraram que a sedação com sevoflurano foi associada a um 
menor tempo de despertar e de extubação, bem como a um menor consumo de opioides do que aquela com propofol ou midazolam. ${ }^{10}$ Estudos com crianças também mostraram resultados positivos. ${ }^{11}$ Apesar dos resultados promissores encontrados nestes estudos iniciais, mostrando que há espaço para o uso de agentes anestésicos voláteis nas UTIs, mais estudos são necessários para confirmar a segurança e a viabilidade do uso destes anestésicos por tempo prolongado em pacientes críticos. ${ }^{12}$

\section{Avaliação, controle e manejo da sedação, analgesia e bloqueio neuromuscular na UTI}

Alcançar adequada, mas não excessiva, sedação em pacientes críticos é um processo complexo. Analgésicos e sedativos empregados neste contexto são extremamente potentes e as necessidades e o metabolismo destas drogas são imprevisíveis. Os médicos devem ter consciência dos efeitos de cada droga e devem empregar estratégias que maximizem benefícios enquanto minimizam os riscos.

Tanto o excesso de sedação quanto a sedação insuficiente são danosos. Para a maioria dos pacientes, as metas de sedação visam aliviar a ansiedade, promover o sono, facilitar os cuidados de enfermagem e a ventilação.

Considerando que as condições clínicas e os graus de estímulo estão sempre em mutação, os níveis de sedação e analgesia devem poder ser alterados rapidamente, prevenindo efeitos excessivos ou insatisfatórios e mantendo simultaneamente a estabilidade hemodinâmica. Para tanto, uma abordagem para titulação das drogas é necessária.

A avaliação dos pacientes carece de medidas objetivas, confiáveis e reprodutíveis para o controle da profundidade da sedação, bem como para a eficácia da analgesia.

As ferramentas de avaliação da dor incluem a autoavaliação (muitas vezes utilizando uma escala analógica ou numérica de dor) para pacientes comunicativos e escalas de dor que incorporam respostas comportamentais, como fácies, postura no leito e grau de agitação, e medidas das respostas fisiológicas ao estresse/ estimulação simpática, para pacientes não comunicativos. ${ }^{13} \mathrm{O}$ uso das ferramentas de autoavaliação frequentemente é prejudicado em pacientes críticos, sendo muitas vezes difícil quantificar a sua experiência subjetiva à dor. Infelizmente, este caráter subjetivo da dor é considerado o mais importante.

A avaliação do nível de sedação se baseia fundamentalmente na observação clínica. Essa abordagem envolve a utilização de escalas/ escores para avaliação do grau de sedação/ agitação (por exemplo, escala de sedação de Ramsay (Quadro 4), escala de agitação-sedação de Richmond (Quadro 5)). Algumas escalas incorporam a avaliação da resposta a crescentes estímulos nocivos e uma breve avaliação da cognição para definir níveis de consciência. ${ }^{13}$

Muitas escalas de sedação/agitação foram extensivamente testadas e validadas. No entanto, essas escalas não fornecem medição contínua da profundidade da sedação e estão sujeitas à variabilidade intra e interobservador. Além disso, embora estas escalas estimem o grau de sedação, elas geralmente não avaliam se o paciente está orientado, delirante ou com dor (limitando sua utilidade, porque muitas vezes não é possível saber se a falta de efetiva sedação é decorrente de delirium ou dor). Por isso, há um crescente interesse no uso de medidas objetivas da consciência e função cerebral como os métodos eletrofisiológicos (por exemplo, análise do índice bispectral do eletroencefalograma) para controlar a profundidade da sedação. No entan-

Quadro 4. Escala de sedação de Ramsay

\begin{tabular}{|c|c|}
\hline 1 & Ansioso, agitado ou inquieto. \\
\hline 2 & Cooperativo, orientado e tranquilo. \\
\hline 3 & Sedado, porém responde às ordens verbais. \\
\hline 4 & $\begin{array}{l}\text { Sedado, com resposta rápida ao leve estímulo glabelar } \\
\text { ou forte estímulo auditivo. }\end{array}$ \\
\hline 5 & $\begin{array}{l}\text { Sedado, com resposta lenta ao leve estímulo glabelar } \\
\text { ou forte estímulo auditivo. }\end{array}$ \\
\hline 6 & Não responsivo. \\
\hline
\end{tabular}


Quadro 5. Escala de agitação-sedação de Richmond (RASS)

\begin{tabular}{|c|c|c|}
\hline+4 & Combativo. & $\begin{array}{l}\text { Combativo ou violento. Perigo para } \\
\text { a equipe. }\end{array}$ \\
\hline+3 & Muito agitado. & $\begin{array}{l}\text { Retira sondas ou cateteres. } \\
\text { Comportamento agressivo contra } \\
\text { equipe. }\end{array}$ \\
\hline+2 & Agitado. & $\begin{array}{l}\text { Movimentação sem finalidade } \\
\text { frequente. Assincronia com } \\
\text { ventilador. }\end{array}$ \\
\hline+1 & Intranquilo. & $\begin{array}{l}\text { Ansioso e apreensivo. Ausência de } \\
\text { movimentos vigorosos ou agressivos. }\end{array}$ \\
\hline 0 & Alerta e calmo. & \\
\hline-1 & Sonolento. & $\begin{array}{l}\text { Não totalmente alerta. Mantém-se } \\
\text { acordado e com contato visual por } \\
\text { mais de } 10 \text { segundos após uma ordem. }\end{array}$ \\
\hline-2 & Levemente sedado. & $\begin{array}{l}\text { Mantém-se acordado e com contato } \\
\text { visual por menos de } 10 \text { segundos } \\
\text { após uma ordem. }\end{array}$ \\
\hline-3 & $\begin{array}{l}\text { Moderadamente } \\
\text { sedado. }\end{array}$ & $\begin{array}{l}\text { Realiza movimentos após uma } \\
\text { ordem, porém não mantém contato } \\
\text { visual. }\end{array}$ \\
\hline-4 & $\begin{array}{l}\text { Profundamente } \\
\text { sedado. }\end{array}$ & $\begin{array}{l}\text { Apresenta movimentos após } \\
\text { estimulação física. Não responde a } \\
\text { ordens. }\end{array}$ \\
\hline-5 & Não despertável. & Sem resposta a estimulação física. \\
\hline
\end{tabular}

to, os métodos eletrofisiológicos ainda não têm aplicação difundida e necessitam de validação antes que estejam prontos para uso rotineiro. ${ }^{14}$ Maior clarificação do papel destes instrumentos, principalmente no âmbito da segurança dos pacientes, é necessária, assim como ainda é necessário desenvolvimento tecnológico para eliminar artefatos.

Quanto ao bloqueio neuromuscular, um dos maiores problemas é a instituição do bloqueio em um paciente inadequadamente sedado levando a alterações adrenérgicas pelo estresse e transtornos de comportamento a longo prazo. Além disso, há a questão da dose, ou seja, se a transmissão neuromuscular precisa ser totalmente abolida ou apenas parcialmente, sendo esta última a situação mais comum. Diferentemente da sedação, é possível objetivamente controlar a profundidade do relaxamento neuromuscular utilizando um estimulador de nervo periférico. ${ }^{15}$

Em pacientes em uso de bloqueador neu- romuscular nem a analgesia nem o nível de sedação podem ser corretamente avaliados.

Embora muita atenção tenha sido dada ao início e à eficácia da terapia sedativa, a sua descontinuação é uma área de crescente interesse. Sabe-se que a sedação contínua é associada à ventilação mecânica prolongada e ao maior tempo de internação na UTI; especialmente quando associada ao bloqueio neuromuscular, aumenta o número de complicações.

Idealmente, a maioria dos pacientes deve estar acordada ou ser facilmente despertável (Ramsay 2-4). Exceções ficam por conta de pacientes com aumento da pressão intracraniana ou pacientes de difícil ventilação onde a completa sedação (Ramsay 5-6), com ou sem bloqueio neuromuscular, pode ser necessária. Além disso, o nível de sedação exigida pode variar de acordo com a gravidade da doença.

Importantes avanços em sedação e analgesia têm sido alcançados através da titulação de medicações guiada por metas, evitando assim o excesso ou a insuficiência de efeitos. Esta abordagem inclui a definição de períodos durante os quais as medicações são interrompidas a fim de atingir um período de relativo despertar, reduzindo assim a probabilidade de acúmulo de drogas e proporcionando oportunidades adicionais para o desmame ventilatório. Recomenda-se que a sedação seja interrompida diariamente para permitir a avaliação das funções neurológica e respiratória do paciente.

O uso de protocolos de interrupção diária da sedação foi estabelecido na literatura como uma ferramenta eficaz para evitar a sedação excessiva, permitindo tanto uma antecipação do desmame da ventilação/extubação como uma melhor diferenciação entre o excesso de sedação e a disfunção cerebral, e reduzindo o número de exames e os custos para esta diferenciação. ${ }^{16}$

Os três componentes básicos dos protocolos são: 1) avaliações frequentes da dor, ansiedade e agitação utilizando uma escala reprodutível; 2) combinação terapêutica utilizando opioides e sedativos (a escolha de um só fármaco para produzir sedação e analgesia não alcançará as 
metas estabelecidas, pois seus efeitos positivos serão limitados por seus efeitos adversos, além de não existir droga que proporcione ambos os efeitos em potência suficiente); e, mais importante, 3) trabalho multidisciplinar para a avaliação dos efeitos/necessidade das drogas, incluindo a interrupção diária. ${ }^{17}$

Outro aspecto importante da utilização destas drogas na UTI é o desenvolvimento de síndromes de retirada/abstinência de opioides e/ou sedativos que podem ocorrer durante o manejo destas drogas. A prevalência e o momento do seu desenvolvimento ainda são pouco claros, porém a titulação da dose até a retirada após tratamento com altas doses ou por mais de uma semana é recomendada formalmente. ${ }^{18}$ Infelizmente, os efeitos a longo prazo de analgésicos e drogas sedativas na função neuropsicológica dos pacientes da UTI ainda não foram definidos.

\section{Sedação paliativa do paciente terminal}

O conceito de terminalidade envolve aspectos legais, técnicos, culturais e religiosos. Tecnicamente, o paciente terminal é aquele cuja doença é irreversível, quando se esgotam as possibilidades de resgate de sua condição de saúde e a possibilidade de morte próxima parece inevitável e previsível. ${ }^{19}$

Segundo a resolução do Conselho Federal de Medicina no 1.805/2006, na fase terminal de enfermidades graves e incuráveis é permitido ao médico limitar ou suspender procedimentos e tratamentos que prolonguem a vida do paciente desde que seja respeitada a vontade do paciente ou de seu representante legal. Nesta mesma resolução é afirmado que se deve garantir ao paciente terminal os cuidados necessários para aliviar os sintomas que levam ao sofrimento, assegurando, na perspectiva de uma assistência integral, o conforto físico, psíquico, social e espiritual. Desta forma, o tratamento paliativo é parte integrante dos cuidados que se deve prestar aos pacientes com doenças avançadas em fase terminal.
Dentre os diversos tratamentos paliativos, a sedação, com intuito de reduzir a consciência, oferecer conforto e aliviar a angústia do paciente ou outros sintomas intoleráveis e/ou refratários, pode ser utilizada, sendo denominada, neste caso, sedação paliativa. Nesta, os fármacos sedativos são titulados de modo que a consciência seja reduzida apenas até o controle dos sintomas, não devendo causar efeitos adversos que "encurtem" a vida, o que a diferencia plenamente da eutanásia. Quando bem indicada e realizada, a terapia de sedação paliativa não causa redução do tempo de sobrevida. ${ }^{19}$

Apesar de não existir consenso sobre quais os fármacos considerados padrão para a sedação paliativa, de forma geral são administradas as mesmas drogas utilizadas na sedação não paliativa, ou seja, os benzodiazepínicos e os opioides. Em algumas situações, outras drogas como neurolépticos, barbitúricos, propofol, cetamina e anti-histamínicos podem ser utilizadas.

\section{Conclusão}

O manejo da sedação e analgesia na UTI requer a avaliação e o acompanhamento de parâmetros-chave, a fim de detectar e quantificar dor, sedação e agitação. A necessidade frequente de mensuração destes parâmetros reflete a natureza dinâmica dos pacientes críticos. Além disso, a reavaliação constante promove um acompanhamento mais rigoroso da resposta ao tratamento, ajudando a melhor controlar a dor e a agitação e evitando o excesso de sedação.

Embora os médicos intensivistas saibam que o tratamento com sedativos e analgésicos pode influenciar na melhor evolução do quadro clínico de seus pacientes, ainda existem falhas no que concerne ao controle da dor e do estresse. Sendo assim, abordagens abrangentes e estruturadas que enfatizem a detecção e a quantificação da dor, da agitação e da interação paciente-ventilador e avaliem a profundidade da sedação devem ser implantadas. 


\section{Referências}

1. Sessler C, Wilhelm W. Analgesia and sedation in the intensive care unit: an overview of the issues. Crit Care. 2008;12(Suppl 3):S1.

2. Gommers D, Bakker J. Medications for analgesia and sedation in the intensive care unit. Crit Care. 2008;12(Suppl 3):S4.

3. Guedes L, Rebelo H, Oliveira R, Neves A. Regional Analgesia in Intensive Care. Rev Bras Anestesiol. 2012 Sep-Oct;62(5):719-30. http://dx.doi.org/10.1016/S00347094(12)70170-8

4. Ribeiro SF, Pinto JCP, Ribeiro JB, Felix MM, Barroso SM, Oliveira LF, et al. Pain Management at Inpatient Wards of a University Hospital. Rev Bras Anestesiol. 2012;62(5):599-611. http://dx.doi.org/10.1016/ S0034-7094(12)70160-5

5. Benseñor FEM, Cicarelli D. Sedation and Analgesia in Intensive Care. Rev Bras Anestesiol. 2003;53(5):680-93.

6. Wilhelm W, Kreuer S. The place for short-acting opioids: special emphasis on remifentanil. Crit Care. 2008;12(Suppl 3):S5.

7. Slullitel A, Sousa AM. Analgesia, sedation and neuromuscular blockade in the ICU. Medicina, Ribeirão Preto. 1998;31(4):507-16.

8. Weissman C. Sedation and Neuromuscular Blockade in the ICU. Chest. 2005;128(2):477-9.

9. Murray MJ, Cowen J, DeBlock H, Erstad B, Gray AW Jr, Tescher AN, et al. Clinical practice guidelines for sustained neuromuscular blockade in the adult critically ill patient. Crit Care Med. 2002;30(1):142-56.

10. Mesnil M, Capdevila X, Bringuier S, Trine PO, Falquet Y, Charbit J, et al. Long-term sedation in intensive care unit: a randomized comparison between inhaled sevoflurane and intravenous propofol or midazolam. Intensive Care Med. 2011;37(6):933-41.

11. Sackey PV, Martling CR, Radell PJ. Three cases of PICU sedation with isoflurane delivered by the 'AnaConDa'. Paediatr Anaesth. 2005;15(10):879-85.

12. Bracco D, Donatelli F. Volatile agents for ICU sedation? Intensive Care Med. 2011;37(6):895-97.

13. Sessler C, Grap M, Ramsay M. Evaluating and monitoring analgesia and sedation in the intensive care unit. Crit Care. 2008;12(Suppl3):S2.

14. Moritz RD. Sedation and Analgesia in ICU: Old Drugs - New Tendencies. Rev Bras Ter Intensiva. 2005;17(1):52-5.

15. Amaral JLG, Issy AM, Conceição AN, et al. Recomendações da Associação de Medicina Intensiva Brasileira sobre Analgesia, Sedação e Bloqueio Neuromuscular em Terapia Intensiva. Associação de Medicina Intensiva Brasileira; 1999.

16. Schweickert W, Gehlbach B, Pohlman A, Hall JB, Kress JP. Daily interruption of sedative infusions and complications of critical illness in mechanically ventilated patients. Crit Care Med. 2004;32(6):1272-6.

17. Schweickert WD, Kress JP. Strategies to optimize analgesia and sedation. Crit Care. 2008;12(Suppl 3):S6. http://dx.doi.org/10.1186/cc6151

18. Clinical practice guidelines for the sustained use of sedatives and analgesics in the critically ill adult. ASHP Therapeutic Guidelines; 2002:634-60.

19. Nogueira FL, Sakata RK. Palliative Sedation of Terminal ill Patients. Rev Bras Anestesiol. 2012;62(4):580-92. 